\title{
NON-SELECTIVE WEED CONTROL
}

\author{
F. A. MeEklah \\ Invermay Research Station, Private Bag, Mosgiel
}

\section{Summary}

The results are given of a series of field trials studying the effectiveness of several residual soil sterilants for weed control on industrial sites. Simazine at $10 \mathrm{lb}$ per acre gave effective suppression of weeds for 13 months, while $20 \mathrm{lb}$ was effective for 18 months. Monuron was somewhat more variable, $32 \mathrm{lb}$ being satisfactory for 12 to 17 months, while $16 \mathrm{lb}$ lasted only 6 to 11 months.

Observations are recorded of the relative efficiency and necessity of adding other herbicides to long-term soil sterilants in order to gain quicker initial control of vegetation. Amitrole, dichloropropionic acid/amitrole, and paraquat were the most efficient additives studied. The results from two granular compounds are briefly noted. The implications of variation in many environmental factors from one trial site to another are discussed, together with comments on other aspects of industrial weed control.

\section{INTRODUCTION}

RESIDUAL SOIL STERILANTS are widely used in developed countries to keep industrial sites free of weeds. The use of chemicals for this purpose has been shown to be both economic and acceptable when compared with the alternatives of hand-weeding or surfacing with asphalt or concrete.

The industrial concerns and public authorities who form the wide market for this type of work naturally have different ideas as to what constitutes satisfactory vegetation control. In this paper it is assumed that initially $100 \%$ control of vegetation is required, and with due regard to the costs involved this should be extended as long as possible. Although some authorities would require retreatment as soon as control deteriorates to $90 \%$ or $80 \%$, for the purpose of this paper it is assumed that in practically all cases retreatment would be required when control dropped to $70 \%$. For this reason the persistence of chemicals beyond this degree of control is not considered.

The work reported here and the conclusions drawn have been accumulated over a period of several years.

\section{MATERIALS AND METHODS}

All treatments are expressed as $\mathrm{lb}$ active ingredient per acre: all were applied in a minimum of 100 gal water per acre.

The soil on trial sites was classified by mechanical analysis (see Table 1); in addition the cation exchange capacity was recorded (also in Table 1). Some trial sites were adjacent and the results are from a composite sample. 


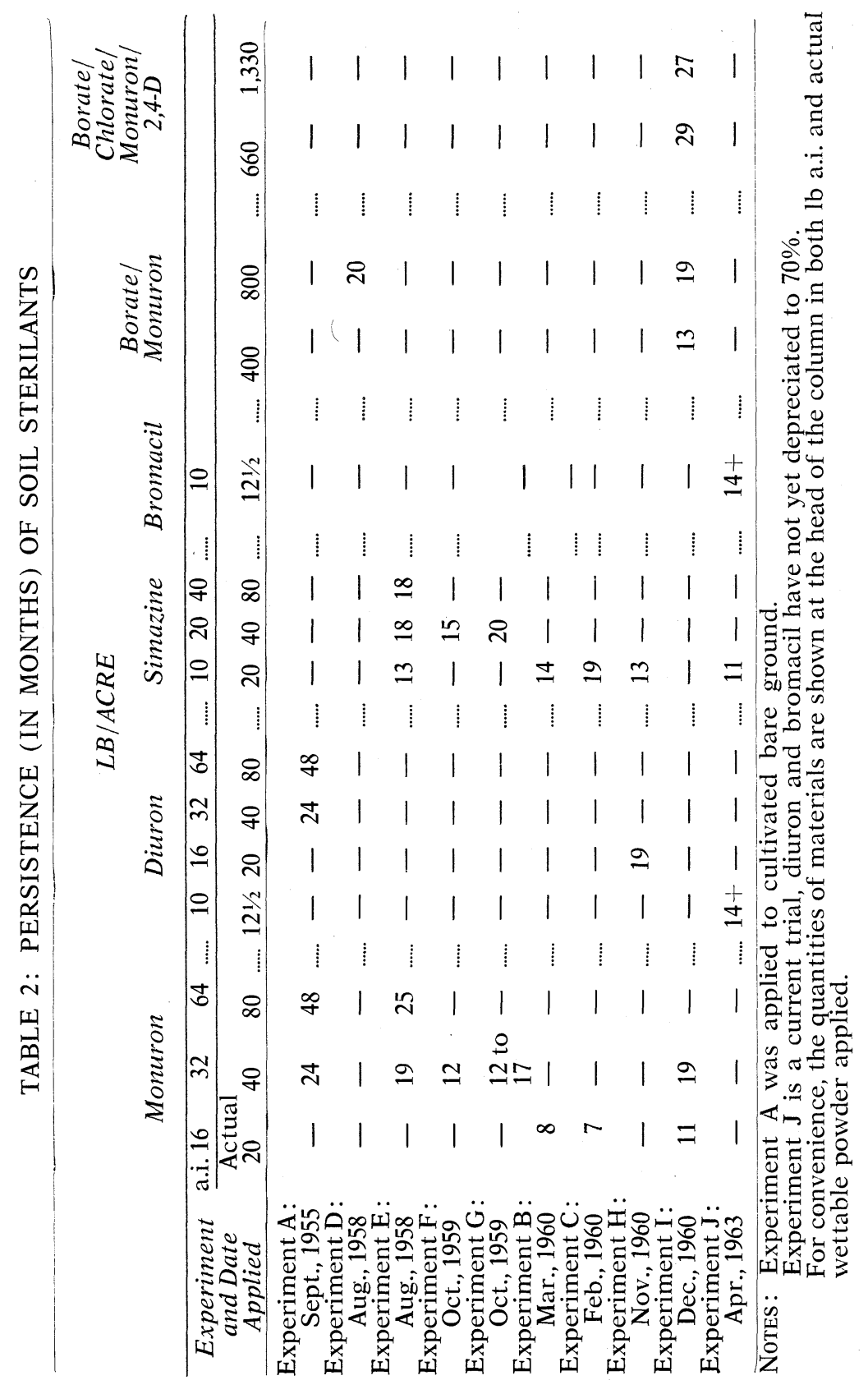

64 
TABLE 1: SOIL MECHANICAL ANALYSIS OF TRIAL SITES

\begin{tabular}{|c|c|c|c|c|}
\hline Site & & & $\begin{array}{c}\text { Texture } \\
\text { Classification }\end{array}$ & $\begin{array}{c}\text { Cation } \\
\text { Exchange Capacity }\end{array}$ \\
\hline $\begin{array}{l}A, B \\
C, D \\
F, \quad \ldots . . . \\
G \\
H, I\end{array}$ & 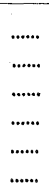 & $\begin{array}{l}\ldots \ldots . \\
\ldots \ldots . . \\
\ldots \ldots . \\
\ldots \ldots . . \\
\ldots \ldots . .\end{array}$ & $\begin{array}{l}\text { Clay loam } \\
\text { Sandy loam } \\
\text { Silt loam } \\
\text { Gravelly sand } \\
\text { Sandy loam } \\
\text { Sandy loam }\end{array}$ & $\begin{array}{l}26.5 \\
16.8 \\
24.4 \\
46.1 \\
19.5 \\
-\end{array}$ \\
\hline
\end{tabular}

Apart from Experiment A which was laid down on freshly cultivated soil, all experimental sites were covered with established vegetation consisting usually of grasses, clovers, and a few weeds.

The treatments, date applied, etc., are given in Table 2, which also gives the results of those treatments. All trials except $A$ and $E$ compared soil sterilants with and without additives (e.g., amitrole paraquat, diquat or fenac) which give quick initial knock-down of vegetation. Two trials compared granular soil sterilants containing monuron plus additives to gain initial control. The granular compounds were applied at rates sufficient to bring their monuron content approximately up to the levels of 16 and $32 \mathrm{lb}$ monuron per acre to compare with the monuron applied as a wettable powder.

The results of experiments are compared on the basis of length of persistence in months to the point where efficiency drops below $70 \%$ in maintaining completely bare ground assessed visually (see Table 2).

\section{RESULTS}

It can be seen that considerable variation occurred from site to site. A brief approximation of results shows that $10 \mathrm{lb}$ simazine persisted for 12 months (the result in Trial C is considered anomalous ), $20 \mathrm{lb}$ for 18 months, while $16 \mathrm{lb}$ monuron persisted for only 7 to 11 months, and $32 \mathrm{lb}$ for 12 to 19 months. Diuron $10 \mathrm{lb}$ persisted for over 14 months, $16 \mathrm{lb}$ for 19 months; bromacil at $10 \mathrm{lb}$ has also persisted for over 14 months.

Results with monuron were more variable than with simazine and generally this material was inferior to simazine, while diuron appeared similar to simazine or better, as in Trial $\mathrm{J}$ : however, in Trial A where monuron and diuron were compared on cultivated bare ground there were no differences. Borate/monuron $\left(40 \% \quad \mathrm{~B}_{2} \mathrm{O}_{3}\right.$ and $4 \%$ monuron) at $400 \mathrm{lb}$ and $800 \mathrm{lb}$ gave results similar to monuron at 16 and $32 \mathrm{lb}$, while chlorea at 660 and $1,330 \mathrm{lb}$ was markedly better. Initial knock-down by chlorea granules was equal to that given by monuron plus amitrole 4 or $8 \mathrm{lb}$ one month after application, while borate/monuron took at least 2 months to gain control.

\section{AdDITIVES}

It was found that additives to gain quick initial control of vegetation were necessary with simazine. In Trial $\mathrm{H}$, it was noted that a lag occurred between the rapid kill by diquat and the slow takeover by simazine. Thus amitrole $5 \mathrm{lb}$ was better than diquat $1 \frac{1 / 2}{2}$ to $3 \mathrm{lb}$, but no better than paraquat $1 \frac{1 / 2}{2}$ to $3 \mathrm{lb}$. Fenac as an additive was poor. Taking into consideration further initial vegetation control trials, not reported here, which have been conducted at 
Invermay the best additives are considered to be amitrole $5 \mathrm{lb}$, paraquat $2 \mathrm{lb}$, or dichloropropionic acid $7.4 \mathrm{lb}+$ amitrole $2 \mathrm{lb}$.

On some sites only small advantage was gained through using additives with the more soluble monuron or diuron, but it is thought that the soil moisture status was particularly favourable in these cases.

\section{DISCUSSION}

In an excellent review of soil acting herbicides, Holly (1962) points out that organic matter content, cation exchange capacity, exchangeable calcium, total exchangeable bases, moisture equivalent, and free drainage value are all soil properties highly and positively correlated with the dose required to produce a given level of effect. These soil properties are all highly correlated among themselves, but variation in response may be attributed to adsorption on the organic matter.

In this series of trials reported, however, there are some anomalies in response, and poor correlation between soil mechanical analysis, cation exchange capacity and herbicidal response. The rate of re-establishment of vegetation on a treated site is not only related to the nature and quantity of sterilants applied but also to the complex of environmental conditions governing the normal establishment and rate of growth of vegetation on that site.

Each site therefore has a "biotic potential" resulting from a wide variety of factors - e.g., soil moisture, soil type, organic matter, viable seed population and climate or season - and the general biotic potential of a site is probably more important than any one of those single factors.

Thus a site with high biotic potential needs a higher dosage rate to maintain a given period of efficient soil sterilization, or conversely, for a given dosage rate sites of high biotic potential will give proportionately shorter periods of efficient soil sterilization.

Results proved superior on cultivated ground; a heavy rate of monuron and diuron ( $64 \mathrm{lb}$ ) achieved satisfactory control for four years, while a similar rate of monuron applied to established vegetation achieved only half this result - i.e., 2 years. In Trial $\mathrm{E}$ simazine was applied without additives with the result that all rates failed to persist as long as may have been expected. Often heavy rates failed through invasion of various rhizomatous or stoloniferous species such as Californian thistles or buttercups. Monuron and diuron often failed through invasion by plantains.

Monuron as an additive in granular soil sterilants gave similar results to the common wettable powder formulation in the case of borate/monuron, but much better results with granules of the borate/chlorate/monuron/2,4-D mixture (borate 70.5\%/chlorate 38\%/ monuron 2.4\%/2,4-D 1\%). However, initial knock-down may be a problem on dry sites with these materials at the (normally) much lower commercial rates recommended, particularly with borate/ rnonuron.

Jit is considered significant that chlorea granules applied at rates giving similar quantities of monuron per acre, gave much better results than that rate of monuron wettable powder applied as a spray with amitrole as an additive. This result appears to give support to the belief that borate inhibits bacterial action that could break down the organic herbicides. Of more general importance is that this result indicates that wider use could be made of granular compounds, particularly on small industrial sites where the visit of a spray contractor may prove uneconomic in application costs owing to the small area involved. In addition, maintenance of a 
well-sprayed area could be effected by spot application of granular compounds by unskilled labour.

Finally, the trial currently being conducted shows that bromacil is much superior to diuron or simazine in maintaining bare ground. Also of interest is the fact that invading species tend to be white clover and grasses rather than the docks and other weeds usually found in the aftermath of industrial soil sterilization work.

\section{CONCLUSIONS}

Briefly these points were derived from Invermay trials:

(1) A general summary is that $10 \mathrm{lb}$ simazine $=13$ months effective soil sterilization (i.e., over $70 \%$ bare ground).

$20 \mathrm{lb}$ simazine $=18$ months.

$16 \mathrm{lb}$ monuron $=7$ to 11 months.

$32 \mathrm{lb}$ monuron $=12$ to 19 months.

$10 \mathrm{lb}$ bromacil $=14$ (plus) months.

(2) Diuron appears more efficient than monuron and similar to simazine when compared on an active ingredient basis. Bromacil is more efficient than simazine and diuron.

(3) Additives are necessary to achieve maximum efficiency from soil sterilants, particularly simazine. These additives in no way adversely affect the persistence of soil sterilants. Paraquat, amitrole, and dichloropropionic acid/amitrole were the most efficient additives examined.

(4) Increases in soil sterilant dosage are not followed by pro rata increases in length of persistence.

(5) Application to cultivated ground is probably the only way to get maximum efficiency from rates of 32 to $64 \mathrm{lb}$ of soil sterilants.

(6) Intelligent use of specific herbicides against re-establishing species will materially prolong the effect of high rates of soil sterilants.

(7) Large clumps of cocksfoot need individual coverage.

\section{ACKNOWLEDGEMENTS}

The author wishes to thank the staff of the Invermay Research Station and the South Island Soil Testing Station for their assistance in this work, also M. S. Foreman who commenced the investigations on Trial A.

\section{REFERENCE}

Holly, K., 1962: Industrial Weed Control Symposium. Proc. Sixth Brit. Weed Control Conf., pp. 467-77. 